\title{
Role of ultrasonogram in chronic lower abdominal pain: special reference to gyenecologoical problems
}

\author{
Chandran $\mathbf{R}^{1}$, Verma $\mathbf{M}^{2}$ \\ ${ }^{1}$ Dr. Rabindran, Consultant Neonatologist, Billroth Hospital, Chennai, India, ${ }^{2}$ Mrs. Mamta Verma, Associate Professor in \\ Nursing, AIIMS, Saket Nagar, Bhopal, MP, India.
}

Address for Correspondence: Dr Rabindran Chandran, E-mail: rabindranindia@yahoo.co.in

\begin{abstract}
Abdominal Pain is very common reason for Out Patients Department and ward visit. In Pediatric population almost more than half cases are not having anyu specific reason for that. These are classified as Functional Abdominal pain. Many times patients insist for radiographic evaluation. It is worthy to check if there is any gyenecological issues in these cases.
\end{abstract}

Key words: Abdominal pain, Chronic abdominal pain, Ultrasonogram

\section{Introduction}

Abdominal pain is a common problem \& constitutes about $3 \%$ of the hospital visit among adults [1]. It may be acute or chronic. Chronic abdominal pain is defined as continuous or intermittent abdominal discomfort lasting for more than six months. It may occur due to problems of the gut, biliary tract, pancreas, gynaecological or genitourinary origin. Sometimes Chronic abdominal pain may be part of a functional syndrome [2]. The term "chronic abdominal pain" also includes "recurrent abdominal pain," which is characterised by more than 3 episodes of abdominal pain; severe pain sufficient to affect daily activities; symptoms lasting more than 3 months; and absence of any organic cause [3]. Chronic abdominal pain usually occurs beyond 5 year of age \& nearly $10 \%$ of children require detailed evaluation.

The usual Presenting features of chronic abdominal pain include undifferentiated abdominal pain (Functional, inflammatory bowel disease, coeliac disease, mechanical obstruction, irritable bowel syndrome) [4], intestinal colic, symptoms suggestive ofCrohn's disease, pelvic or iliac fossa pain (gynaecological disease, Crohn's disease, functional syndromes), dyspepsia, biliary symptoms, right upper quadrant pain \& renal tract symptoms. Majority will subside with appropriate symptomatic treatment. Howeversigns like iron deficiency anaemia, blood in stool, awakening at night with gastrointestinal

Manuscript received: $18^{\text {th }}$ July 2017

Reviewed: $28^{\text {th }}$ July 2017

Author Corrected: $4^{\text {th }}$ August 2017

Accepted for Publication: $10^{\text {th }}$ August 2017

Obsgyne Review: Journal of Obstetrics and Gynecology symptoms, unexplained weight loss, family history of colorectal cancer \& age at onset over 50 years should provoke detailed workup study [5,6]. The evaluation of Chronic Abdominal Pain will lead to an etiological diagnosis which may involve variedsystems. Genitourinary causes include Congenital abnormalities, Endometriosis, Ovarian cyst, ovarian cancer, Renal calculi, Sequelae of acute Pelvic inflammatory disaeases; Gastrointestinal causes include Celiac disease, Chronic appendicitis, cholecystitis, hepatitis, pancreatitis, pancreatic pseudocyst, Colonic/ gastric/ pancreatic cancer, Crohn disease, Granulomatous enterocolitis, Hiatus hernia with reflux, Intestinal Tuberculosis, Lactose intolerance, Parasitic infestation (giardiasis), Peptic ulcer disease, Postoperative adhesive bands \& Ulcerative colitis.

Systemic disorders like Abdominal epilepsy,Familial angioneurotic edema, Familial Mediterranean fever, Food allergy, Immunoglobulin A-associated vasculitis (formerly Henoch-Schönlein purpura), Lead poisoning, Migraine equivalent, Porphyria and Sickle cell disease also present with chronic abdominal pain [7].

Hence the evaluation of chronic abdominal pain requires athorough understanding of the etiopathogenesis, epidemiologic spectrum \& a knowledge of the varied patterns of presentation. There are multiple modalities of investigations including conventional abdominal radiographs, ultrasonogram, computed tomography, magnetic- resonance imaging, Lapaoroscopy and endoscopy. Sometimes an invasive 


\section{Review Article}

procedure like Biopsy may be required for an etiological diagnosis for chronic abdominal pain. Abdominal ultrasound is a common imaging test used to examine various abdominal organs [8]. It is remains as choice of investigation in the initial test for patients presenting with right upper quadrant pain. It is consider choice of test with compression for children below 14 years presenting with right lower quadrant pain. The American Council of Radiology has recommended ultrasound as the initial imaging study for right upper quadrant pain, regardless of presence or absence of fever, raised white blood cell count or a positive Murphy's sign. A recent meta-analysis done on 2012 has found that ultrasound has a sensitivity of $81 \%$ \& specificity of $83 \%$ for diagnosing acute cholecystitis [9].

Use of Ultrasonogram for chronic abdominal painhas many advantages like high-resolution imaging technique, good versatility \& real-time imaging capability, wide availability, inexpensive, painfree, non - invasiveness, easy-to-use, extremely safe and most important the absence of any ionizing radiation. It is useful to find the cause of abdominal pain, kidney infections, diagnose \& monitor tumors, ascites, renal \& gallstones, to evaluate pelvic or scrotal pain, abscesses, inflamed appendix, identify abnormal abdominal fluid $\&$ evaluating those presenting with pain \& vomiting. It gives a clear picture of soft tissues pathology missed in $\mathrm{X}$-ray images. Because of its real-time imaging, it is useful for FNAC and fluid aspiration. Its real-time dynamic examination helps analyse bowel motility \& blood flow [10].

Depending upon the location of the symptoms ultrasonogram can be done like Upper abdominal ultrasound, Pelvic abdominal ultrasound, transvaginal ultrasound, transrectal ultrasound, endoscopic ultrasound. Upper abdominal ultrasound is indicated for the evaluation of Right Upper Quadrant/ epigastric pain along with raised liver/ pancreatic enzymes. For lower abdominal pain, Pelvic abdominal ultrasound, transvaginal or transrectal ultrasound can be done [11].

An abdominal ultrasound can also be used as a diagnostic tool for conditions such as Abdominal aortic aneurysm, Hydronephrosis, Portal hypertension, Obstruction of bile ducts, Cirrhosis, blood clot/ fluid in abdominal cavity, hernia, kidney blockage or tumour. Ultrasound is useful for suspected Crohn's disease due to its high negative predictive value [12,13]. Pelvic ultrasound is the most important investigation for women of reproductive age with suspected endometriosis,ovarian or other adnexal disease [14].
Renal ultrasound is useful for ruling out renal obstruction, intra-renal calculi \& renal masses [15]. Visualization of morphologic changes in chronic pancreatitis by transabdominal ultrasound has varying diagnostic accuracy with a sensitivity of $70 \%$ to $80 \%$ $[16,17]$. One large study reported sensitivities for Ultrasound to be around $85 \%$ for features calcifications, pancreatic duct dilations \& cysts which is comparable to CT [24]. Ultrasonogram also helps in assessing the severity of disease as in chronic pancreatitis $[18,19]$.

Here as the disease worsens, the pancreas loses its hyperechogenicity \& becomes progressively heterogeneous due to focal inflammation [20,21]. This progressive inflammation \& fibrosis \& irreversible structural changes involving parenchyma \& pancreatic duct can be evaluated using Ultrasonogram [22,23]. It also detects late stages where there is irregularly dilated Main pancreatic duct, Pseudocysts with pancreatic \& intraductal calculi and pancreatic atrophy [20,24].

Though extremely useful, ultrasound is highly operator dependent. As Ultrasound waves are disrupted by air or gas it can not be used for imaging air-filled bowel or organs obscured by the bowel. Similarly for obese patients, imaging can be difficult due to greater amounts of tissue attenuating the sound waves. Though ultrasound cannot differentiate a benign or malignant tumor, it can be used during biopsy guiding the placement of the needle. It is also useful to drain fluid from a cyst or abscess $\&$ to examine blood flow inside the abdomen.

Ultrasonogram among children is different as several factors are unique including increased radiosensitivity to ionizing radiation, smaller body size \& less body fat [25]. The spectrum of the Chronic Abdominal Pain is also different among Children. The different types of chronic abdominal pain among children are Abdominal migraine, Functional abdominal pain, Functional dyspepsia \& Irritable bowel syndrome. Common causes of chronic abdominal pain in children include Inflammation of esophagus/ stomach, parasitic infections, urinary tract infection, Menstrual cycle, Anxiety \& stress from problems at school or home, Constipation, lactose intolerance, peptic ulcer, Crohn disease, Kidney stones \& gallstones.

Functional abdominal painis a very common disorder affecting 1 out of 5 children \& adolescents. Doppler ultrasound is a technique which assesses blood flow through arteries \& veins in abdomen, liver and kidneys. It is useful to evaluate blockages to blood flow, clots, narrowing of vessels, tumors, congenital vascular 


\section{Review Article}

malformations, reduced or absent blood flow to various organs, greater than normal blood flow to different areas commonly associated with infections. Chronic pain caused by vascular conditions such as mesenteric artery stenosis ('mesenteric angina') are initially best investigated with Doppler ultrasound.

Endoscopic Ultrasonogram with characterization of ductal \& parenchymal changes with or without the aid of weighted scores like Rosemont score is currently the gold standard for chronic pacreatitis imaging [26]. Its diagnostic quality is comparable to computed tomography (CT) \& magnetic resonance imaging (MRI) $[27,28]$. Endoscopic ultrasonogram changes correlates with histopathologic findings \& extent of exocrine dysfunction [27,29].

Of late modern Ultrasound probes are developed with dynamic frequencies, better depth-focusing technology, high-frequency, significantly better noise reduction \& improved resolution are accessible. This helps in better characterization of lesions especially calcifications, where overall reduction of random noise features is important.

Funding: Nil, Conflict of interest: None initiated, Permission from IRB: Yes

\section{References}

1. Viniol A, Keunecke C, Biroga T, Stadje R, Dornieden K, Bösner S, Donner- Banzhoff $\mathrm{N}$, Haasenritter J, Becker A. Studies of the symptom abdominal pain--a systematic review and meta-analysis. Fam Pract. 2014 Oct; 31(5):517-29. doi: 10.1093 / fampra / cmu036. Epub2014 Jul 1.

2. Mendelson R. Imaging for chronic abdominal pain in adults. AustPrescr. 2015 Apr;38(2):49-54. Epub 2015 Apr 1.

3. Gijsbers CF, Kneepkens CM, Schweizer JJ, et al. Recurrent abdominal pain in 200 children: somatic causes and diagnostic criteria. Acta Paediatr 2011; 100:e208.

4. Rome Foundation . Guidelines--Rome III diagnostic criteria for functional gastrointestinal disorders. J Gastrointestin Liver Dis 2006;15:307-12.

5. O'Connor OJ, McSweeney SE, McWilliams S, O'Neill S, Shanahan F, Quigley EM, Maher MM.Role of radiologic imaging in irritable bowel syndrome: evidence-based review. Radiology.2012Feb;262(2): 485 - 94. doi: 10.1148/radiol.11110423. Epub 2011 Dec 9.

Obsgyne Review: Journal of Obstetrics and Gynecology
6. Whitehead WE, Palsson OS, Feld AD, Levy RL, VON Korff M, Turner MJ, Drossman DA. Utility of red flag symptom exclusions in the diagnosis of irritable bowel syndrome. Aliment Pharmacol Ther. 2006 Jul 1; 24 (1):137-46.

7. Greenberger NJ: Sorting through nonsurgical causes of acute abdominal pain. Journal of Critical Illness 7: 1602-1609, 1992.

8. Stoker J, van Randen A, Laméris W, Boermeester MA. Imaging patients with acute abdominal pain. Radiology.2009 Oct;253(1):31-46. doi: 10.1148/radiol. 2531090302.

9. Catalano, M.F., Lahoti, S., Geenen, J.E., and Hogan, W.J. Prospective evaluation of endoscopic ultrasonography, endoscopic retrograde pancreatography, and secretin test in the diagnosis of chronic pancreatitis. GastrointestEndosc. 1998; 48: 11-17

10. Maria Antonietta Mazzei, Susanna Guerrini, Nevada Cioffi Squitieri, Lucio Cagini, Luca Macarini, Francesco Coppolino, Melchiore Giganti, Luca Volterrani. The role of US examination in the management of acute abdomen; Critical Ultrasound Journal 20135(Suppl 1):S6.DOI: 10.1186/2036-7902-5-S1-S6

11. Burges A, Schmalfeldt B. Ovarian cancer: diagnosis and treatment.DtschArztebl Int. 2011 Sep;108(38): 63541.doi: 10.3238/arztebl.2011.0635. Epub 2011 Sep 23.

12. Dong J, Wang H, Zhao J, Zhu W, Zhang L, Gong J, $\mathrm{Li}$ Y, Gu L, Li J. Ultrasound as a diagnostic tool in detecting active Crohn's disease: a meta-analysis of prospective studies.EurRadiol. 2014 Jan; 24(1):26-33. doi: 10.1007/s00330-013-2973-0. Epub 2013 Aug 7.

13. Horsthuis $\mathrm{K}$, Bipat S, Bennink RJ, Stoker J.Inflammatory bowel disease diagnosed with US, MR, scintigraphy, and CT: meta-analysis of prospective studies. Radiology. 2008 Apr; 247(1):64-79. doi: 10. 1148 /radiol.2471070611.

14. Mendelson R. Imaging for chronic abdominal pain in adults. Aust Prescr. 2015 Apr; 38 (2):49-54. Epub 2015 Apr 1.

15. Gray RE, Gaddey HL. RADIOLOGY REPORT: An imaging guide to abdominal pain.J Fam Pract. 2015 May; 64 (5):286-91.

16. Ikeda, M., Sato, T., Morozumi, A., Fujino, M.A., Yoda, Y., Ochiai, M., and Kobayashi, K. Morphologic changes in the pancreas detected by screening 


\section{Review Article}

ultrasonography in a mass survey, with special reference to main duct dilatation, cyst formation, and calcification. Pancreas. 1994; 9: 508-512

17. Martínez-Noguera A, D'Onofrio M. Ultrasonography of the pancreas. 1.Conventional imaging. Abdom Imaging. 2007 Mar-Apr;32(2):136-49.

18. Conwell DL, Lee LS, Yadav D, Longnecker DS, Miller FH, Mortele KJ, Levy MJ, Kwon R, Lieb JG, Stevens T, Toskes PP, Gardner TB, Gelrud A, Wu BU, Forsmark CE, Vege SS. American Pancreatic Association Practice Guidelines in Chronic Pancreatitis: evidence-based report on diagnostic guidelines. Pancreas. 2014 Nov;43(8):1143-62. doi: 10.1097/MPA. 0000000000000237.

19. Drewes, A.M., Frokjaer, J.B., Jørgensen, M.T., Knoop, F., Mortensen, M.B., Schaffalitzky de Muckadell, O., Nøjgaard, C., Olesen, S., Phillipsen, E., and Rasmussen, H. Diagnostik ogbehandling afkronisk pankreatit. Dansk Selskab for Gastro-enterologiog Hepatologi, Aalborg; 2015

20. Bolondi L, Priori P, Gullo L, Santi V, Bassi SL, Barbara L, et al. Relationship between morphological changes detected by ultrasonography and pancreatic exocrine function in chronic pancreatitis. Pancreas 2(2):222-229, 1987.

21. Jones SN, Lees WR, Frost RA. Diagnosis and grading of chronic pancreatitis by morphological criteria derived by ultrasound and pancreatography. ClinRadiol. 1988 Jan;39(1):43-8.

22. De Backer AI, Mortelé KJ, Ros RR, Vanbeckevoort D, Vanschoubroeck I, De Keulenaer B. Chronic pancreatitis: diagnostic role of computed tomography and magnetic resonance imaging. JBR-BTR 85(6):304$310,2002$.
23. Dimcevski G, Erchinger FG, Havre R, Gilja OH. Ultrasonography in diagnosing chronic pancreatitis: new aspects. World J Gastroenterol 19(42):7247-7257, 2013

24. Homma T, Harada H, Koizumi M. Diagnostic criteria for chronic pancreatitis by the Japan Pancreas Society. Pancreas 15(1):14-15, 1997.

25. Balachandran B, Singhi S, Lal S. Emergency management of acute abdomen in children.Indian $\mathrm{J}$ Pediatr. 2013 Mar; 80(3): 226-34. doi: 10.1007/s12098013-0991-1. Epub 2013 Mar 1.

26. Catalano, M.F., Sahai, A., Levy, M., Romagnuolo, J., Wiersema, M., Brugge, W., Freeman, M., Yamao, K., Canto, M., and Hernandez, L.V. EUS-based criteria for the diagnosis of chronic pancreatitis: The Rosemont classification. Gastrointest Endosc.2009; 69:1251-1261

27. Kalmin, B., Hoffman, B., Hawes, R., and Romagnuolo, J. Conventional versus Rosemont endoscopic ultrasound criteria for chronic pancreatitis: Comparing interobserver reliability and intertest agreement. Can J Gastroenterol. 2011; 25: 261-264

28. Pungpapong, S., Wallace, M.B., Woodward, T.A., Noh, K.W., and Raimondo, M. Accuracy of endoscopic ultrasonography and magnetic resonance cholangiopancreato-graphy for the diagnosis of chronic pancreatitis: A prospective comparison study. J Clin Gastroenterol. 2007; 41: 88-93

29. Albashir S, Bronner MP, Parsi MA, Walsh RM, Stevens T. Endoscopic ultrasound, secretin endoscopic pancreatic function test, and histology: correlation in chronic pancreatitis.Am J Gastroenterol. 2010 Nov; 105 (11): 2498-503. doi: 10. 1038/ajg. 2010.274. Epub 2010 Jul 6.

\section{How to cite this article?}

Chandran R, Verma M. Role of ultrasonogram in chronic lower abdominal pain: special reference to gyenecologoical problems. Obs Rev:J obstet Gynecol 2017;3(3):21-24.doi:10.17511/joog.2017.i03.02. 